\title{
Effects of cofD gene knock-out on the methanogenesis of Methanobrevibacter ruminantium
}

\author{
Jian Ma ${ }^{\dagger}$, Xueying Wang ${ }^{\dagger}$, Ting Zhou, Rui Hu, Huawei Zou, Zhisheng Wang ${ }^{*}$, Cui Tan, Xiangfei Zhang, \\ Quanhui Peng, Bai Xue and Lizhi Wang
}

\begin{abstract}
This study aimed to investigate the effects of cofD gene knock-out on the synthesis of coenzyme $F_{420}$ and production of methane in Methanobrevibacter ruminantium (M. ruminantium). The experiment successfully constructed a cofD gene knock-out M. ruminantium via homologous recombination technology. The results showed that the logarithmic phase of mutant M. ruminantium (12 h) was lower than the wild-type (24 h). The maximum biomass and specific growth rate of mutant $M$. ruminantium were significantly lower $(P<0.05)$ than those of wild-type, and the maximum biomass of mutant $M$. ruminantium was approximately half of the wild-type; meanwhile, the proliferation was reduced. The synthesis amount of coenzyme $\mathrm{F}_{420}$ of $M$. ruminantium was significantly decreased $(P<0.05)$ after the cofD gene knock-out. Moreover, the maximum amount of $\mathrm{H}_{2}$ consumed and $\mathrm{CH}_{4}$ produced by mutant were 14 and $2 \%$ of wild-type $M$. ruminantium respectively. In conclusion, cofD gene knock-out induced the decreased growth rate and reproductive ability of $M$. ruminantium. Subsequently, the synthesis of coenzyme $F_{420}$ was decreased. Ultimately, the production capacity of $\mathrm{CH}_{4}$ in $\mathrm{M}$. ruminantium was reduced. Our research provides evidence that cofD gene plays an indispensable role in the regulation of coenzyme $\mathrm{F}_{420}$ synthesis and $\mathrm{CH}_{4}$ production in M. ruminantium.
\end{abstract}

Keywords: cofD gene, Methane, Coenzyme $\mathrm{F}_{420}$, Methanobrevibacter ruminantium, Gene knock-out

\section{Introduction}

The mitigation of greenhouse gases has become a hot topic in recent years owing to their severe environmental impact. Methane $\left(\mathrm{CH}_{4}\right)$ is a strong greenhouse gas, accounting for approximately $16 \%$ of the total global greenhouse gas emissions (calculated as $\mathrm{CO}_{2}$ equivalent). Previously, several studies have been conducted to investigate the reduction of $\mathrm{CH}_{4}$ emissions to attenuate the greenhouse effect (André-Denis et al. 2011; Huang et al. 2020). In animal husbandry production, ruminants, contributing to $33 \%$ of the total $\mathrm{CH}_{4}$ emissions of human

\footnotetext{
*Correspondence: wangzs67@126.com

${ }^{\dagger} J$ ian Ma and Xueying Wang contributed equally in this work Low Carbon Breeding Cattle and Safety Production University Key Laboratory of Sichuan Province, Animal Nutrition Institute, Sichuan Agricultural University, Chengdu 611130, China
}

activities, are important sources of $\mathrm{CH}_{4}$ emissions. On the other hand, approximately $2 \sim 12 \%$ of the gross energy from feed can be transformed into $\mathrm{CH}_{4}$ during the ruminal fermentation of ruminants and exhausted because of unavailability (Johnson et al. 1995). In recent years, various strategies have been researched to inhibit $\mathrm{CH}_{4}$ production in the rumen, such as artificial regulation of ruminal microbiota structure, using the biological inhibitors and vaccines, chemical inhibitors, and nutritional control measures. Unfortunately, the rumen micro-ecosystems can adapt and recover the original methanegenerating level soon after administration (Hook et al. 2010; Martin et al. 2010). Therefore, external regulations can not steadily reduce the $\mathrm{CH}_{4}$ production and emission from ruminants in the long term.

Methanobrevibacter is the dominant archaea in the gastrointestinal tract of herbivorous animals (Cersosimo
Springer Open (c) The Author(s) 2021. This article is licensed under a Creative Commons Attribution 4.0 International License, which permits use, sharing, adaptation, distribution and reproduction in any medium or format, as long as you give appropriate credit to the original author(s) and the source, provide a link to the Creative Commons licence, and indicate if changes were made. The images or other third party material in this article are included in the article's Creative Commons licence, unless indicated otherwise in a credit line to the material. If material is not included in the article's Creative Commons licence and your intended use is not permitted by statutory regulation or exceeds the permitted use, you will need to obtain permission directly from the copyright holder. To view a copy of this licence, visit http://creativeco mmons.org/licenses/by/4.0/. 
et al. 2015). In the rumen, the Methanobrevibacter ruminantium (M. ruminantium) has higher methanogenic activity and adaptability of environmental changes ( $\mathrm{Li}$ et al. 2014). As a kind of hydrogenotrophic methanogen, the M. ruminantium can utilize $\mathrm{H}_{2}$ and $\mathrm{CO}_{2}$ for $\mathrm{CH}_{4}$ production (Danielsson et al. 2012; Benepal 2012). Coenzyme $\mathrm{F}_{420}$ is a key metabolic coenzyme in the process of energy metabolism of hydrogenotrophic methanogens and involved in the critical steps of $\mathrm{CH}_{4}$ generation from $\mathrm{CO}_{2}$ by hydrogen reduction (Eirich et al. 1978). The generation of phosphodiester $\mathrm{F}_{420}-0$ by condensation of L-lactoyl diphosphate guanosine (LPPG) and Fo is a critical process for coenzyme $\mathrm{F}_{420}$ activation (Graupner and White 2001). This reaction is catalyzed by 2-phospho-L-lactate transferase (known as CofD in archaea) (Choi et al. 2001; Graupner et al. 2002). Hence, CofD plays an essential role in the process of $\mathrm{F}_{420}$ biosynthesis. However, at present, few researches have addressed the question of how CofD enzyme affects the synthesis of coenzyme $\mathrm{F}_{420}$, thereby regulating the methanogenic activity and growth of methanogens.

In the current study, a cofD activity deficient $M$. ruminantium strain was constructed by knocking out cofD gene using homologous recombination of the tetracycline resistance gene into the cofD sequence in the chromosome. The polymerase chain reaction and western blotting were performed to verify the success of constructed cofD knock-out strain and disruption of $\operatorname{cof} D$ activity. With the purpose of new molecular target towards mitigation of $\mathrm{CH}_{4}$ emission, the effects of a knocking-out cofD gene on the growth and methanogenic activity of $M$. ruminantium were investigated in anaerobic culture.

\section{Materials and methods}

\section{Bacterial strains and plasmids}

The representative ruminant Methanobrevibacter ruminantium M1 (DSM1093) (this strain have been deposited in a publicly accessible culture collection belonging to the DSMZ) used in this study was obtained from the CSIRO Microbiology Laboratory (Australia) friendly. The plasmid pUC19, pEASY ${ }^{\circledR}$-T1, and pBR322 cloning vector were purchased from JRDUN Biotechnogy Co. Ltd (Shanghai, China). The strain E. coli DH5 $\alpha$ was used as a plasmid cloning host. The pUC18-cofD-tet vector were constructed in this study.

\section{Chemicals and media}

All the chemicals were analytical grade. M. ruminantium strain was cultured in the following liquid medium: yeast extract, $0.2 \mathrm{~g} / \mathrm{L}$; peptone, $0.2 \mathrm{~g} / \mathrm{L}$; $\mathrm{NaHCO}_{3}, 6 \mathrm{~g} / \mathrm{L}$; L-cysteine- $\mathrm{HCl} \cdot \mathrm{H}_{2} \mathrm{O}, 0.35 \mathrm{~g} / \mathrm{L}$; mineral salt solution I, $0.05 \%$; mineral salt solution II, $0.05 \%$; Balch trace element solution, $0.01 \%$, and $0.1 \%$ resazurin
(W/V) $0.001 \%$, in which solutions were prepared previously and stored at $4{ }^{\circ} \mathrm{C}$. In our research, the modified liquid medium (BJ) was supplemented with $0.1 \%$ clarified ruminal fluid (the ruminal fluid was centrifuged at $4{ }^{\circ} \mathrm{C}$ and $13,000 \mathrm{r} / \mathrm{min}$ for $15 \mathrm{~min}$, and the supernatant was collected). Finally, the deionized water was added to a total volume of $1 \mathrm{~L}$. Mineral salt solution I (values in grams per liter): $\mathrm{K}_{2} \mathrm{HPO}_{4} \cdot 3 \mathrm{H}_{2} \mathrm{O}, 7.86$; Mineral salt solution II: $\mathrm{KH}_{2} \mathrm{PO}_{4}, 6 ;\left(\mathrm{NH}_{4}\right) \mathrm{SO}_{4}, 6 ; \mathrm{NaCl}, 12$; $\mathrm{MgSO}_{4}, 1.2 ; \mathrm{MgSO}_{4} \cdot 7 \mathrm{H}_{2} \mathrm{O}, 2.5 ; \mathrm{CaCl}_{2}, 1.2 ; \mathrm{CaCl}_{2} \cdot 2 \mathrm{H}_{2} \mathrm{O}$, 1.6; Balch trace element solution: nitro acetic acid, 1.5; $\mathrm{MgSO}_{4} \cdot 7 \mathrm{H}_{2} \mathrm{O}, 3.0 ; \mathrm{NaCl}, 1.0 ; \mathrm{MnSO}_{4} \cdot 2 \mathrm{H}_{2} \mathrm{O}, 0.5$; $\mathrm{FeSO}_{4} \cdot 7 \mathrm{H}_{2} \mathrm{O}, 0.1 ; \mathrm{CoCl}_{2} \cdot 6 \mathrm{H}_{2} \mathrm{O}, 0.1 ; \mathrm{CaCl}_{2} \cdot 2 \mathrm{H}_{2} \mathrm{O}, 0.1$; $\mathrm{ZnCl}_{2}, 0.1 ; \mathrm{CuSO}_{4} \cdot 5 \mathrm{H}_{2} \mathrm{O}, 0.01 ; \mathrm{AlK}\left(\mathrm{SO}_{4}\right)_{2}, 0.01 ; \mathrm{H}_{3} \mathrm{BO}_{3}$, $0.01 ; \mathrm{Na}_{2} \mathrm{MoO}_{4} \cdot 2 \mathrm{H}_{2} \mathrm{O}, 0.01$. The liquid medium $\mathrm{pH}$ was adjusted and maintained at $6.9 \sim 7.0$. The medium was prepared under an $80 \%$ nitrogen and $20 \%$ carbon dioxide gas phase by the Hungate technique as modified Bryant and Robinson (Balch and Wolfe 1977). The aliquots of the medium were separated under strictly anaerobic condition via autoclaving at $124{ }^{\circ} \mathrm{C}$, and all roller tubes and vials were capped with rubber plugs and aluminum caps. For E. coli incubation, a LuriaBertani (LB) solid medium containing $10 \mathrm{~g} / \mathrm{L}$ tryptone, $5 \mathrm{~g} / \mathrm{L}$ yeast extract, and $10 \mathrm{~g} / \mathrm{L} \mathrm{NaCl}$ was used and agar was added to the medium to a final concentration of $2 \%$ for preparation of solid medium.

\section{Preparation of target gene cofD fragment}

The $M$. ruminantium strain was inoculated in deoxygenated sterilized Hungatetubes contained with liquid medium for recovery and culture at $39{ }^{\circ} \mathrm{C}$ for $30 \mathrm{~h}$. Genomic DNA was extracted from collected thalli cells using the Bacterial Genomic DNA Extraction Kit (Takara, Beijing, China). The cofD gene was amplified by PCR using primers cofD5'and cofD3' (Table 1). Amplification conditions were set at $94{ }^{\circ} \mathrm{C}$ for $10 \mathrm{~min}$ followed by 30 cycles at $94{ }^{\circ} \mathrm{C}$ for $45 \mathrm{~s}, 60^{\circ} \mathrm{C}$ for $45 \mathrm{~s}, 72{ }^{\circ} \mathrm{C}$ for $45 \mathrm{~s}$, and $72{ }^{\circ} \mathrm{C}$ for $10 \mathrm{~min}$. Amplified cofD gene segments were excised from agarose gel and purified by QIAquick PCR purification Kit (Qiagen, Hilden, Germany). The target gene cofD was ligated with the vector pEASY-T1 at a molar ratio of $3: 1$ at $37{ }^{\circ} \mathrm{C}$ for $15 \mathrm{~min}$. The ligation products were transformed into E. coli $\mathrm{DH} 5 \alpha$ strain and screened with Blue-White Screenings on the LB plates containing Amp, IPTG, and X-gal. The transformed bacteria were amplified in LB liquid medium (containing $0.1 \%$ ampicilin), $37^{\circ} \mathrm{C}, 250 \mathrm{r} / \mathrm{min}$ shock culture for $2 \mathrm{~h}$, then verified by colony PCR. Positive clones were sent to the BGI Company (Beijing Genomics Institute) for sequencing, and homology comparisons were performed on GeneBank. 
Table 1 List of reference genes and primers

\begin{tabular}{ll}
\hline Reference genes & Sequence $\left(\mathbf{5}^{\prime} \rightarrow \mathbf{3}^{\prime}\right)$ \\
\hline cofD-F & CGGAATTCATGATAACCATCCTTTCCG \\
cofD- $\mathrm{b}$ & CGCTCGAGCAGTTCTAACACCACTTTTGC \\
tet- $\mathrm{F}$ & CGCATCGATTAGTTCTCATGTTTGACAGCTTATCTTCGAT \\
tet- $\mathrm{R}$ & TTAATCGATTCAGGTCGAGGTGGCCCGGCT \\
\hline
\end{tabular}

\section{Amplification of tetracycline resistance gene}

Methanogens belong to the gram positive bacteria, and the tetracycline resistance gene can be expressed in gram positive bacteria according to its characteristics. Thus, in this experiment, it is selected as a marker gene for constructing a vector. The Cla I cleavage site was added to the two specific primers tet-F and tet- $\mathrm{R}$ of the tetracycline resistance gene (Table 1 ). The tetracycline resistance gene was specifically amplified using pBR322 plasmid DNA as a template by YEATaq polymerase (Takara, Beijing, China). The purified PCR product was ligated to the cloning vector $\mathrm{pEASY}-\mathrm{T} 1$ at $37{ }^{\circ} \mathrm{C}$ for $15 \mathrm{~min}$. The resulting plasmid was transformed into E. coli $\mathrm{DH} 5 \alpha$ strain and screened with ampicillin. The extracted plasmid was named pEASY-T1-cofD and pEASY-T1-tet and sequenced.

\section{Construction of recombinant plasmid pUC18-cofD-tet}

The constructed pEASY-T1-cofD recombinant plasmid and pUC18 plasmid vector were double digested with EcoRI and HindШ, respectively. After the pEASY-T1cofD product was detected by gel electrophoresis, the cofD band was recovered and inserted into the pUC18 vector (double enzyme digested) to construct a pUC18cofD recombinant plasmid. The constructed pEASY-T1tet and pUC18-cofD plasmid DNAs were cleaved by Cla I respectively. After the detection of pEASY-T1-tet by electrophoresis, the tet band was recovered and inserted into the pUC18-cofD recombination vector, which was digested at $20{ }^{\circ} \mathrm{C}$ for $25 \mathrm{~min}$. The resulting plasmid was transformed into $E$. coli DH5 $\alpha$ strain and screened with Blue-White Screenings to select recombinant.

\section{Identification of cofD gene knock-out strains}

The constructed pUC18-cofD-tet recombinant plasmid was transformed into the M. ruminantium by electroporation. The mutant strains were screened using tetracycline plates. After anaerobic culture, the knock-out and wild $M$. ruminantium bacterial fluid were collected and the DNA and RNA were extracted. The cofD gene expression and the CofD enzyme protein expression were determined by qRT-PCR and western blotting. The housekeeping gene glyceraldehyde-3-phosphate dehydrogenase (GAPDH) was used as a normalizing control.
Comparison of cofD gene knock-out and wild-type strains

The mutant and wild-type $M$. ruminantium were anaerobically inoculated into Hungate tubes which equipped with optimized liquid medium. The inoculation amount of growth strains was $0.6 \mathrm{~mL}$ for each serum bottle and cultured at different time points $(12,24,36,48,96 \mathrm{~h})$ with three replicates at each time point. After inoculation, $40 \mathrm{kpa}$ of $\mathrm{CO}_{2}$ was added to the Hungate tube, $\mathrm{H}_{2}$ was added to a pressure of $200 \mathrm{kpa}$, and the plate was placed in a constant-temperature incubator with a horizontal swing $(40 \mathrm{rpm} / \mathrm{min})$. The growth curve of $M$. ruminantium was measured using a spectrometer at a wavelength of $600 \mathrm{~nm}$. The gas composition was analyzed by gas chromatography, including the respective proportions of the $\mathrm{H}_{2}, \mathrm{CO}_{2}$, and $\mathrm{CH}_{4}$. The absorbance of coenzyme $\mathrm{F}_{420}$ was measured by a spectrometer at a wavelength of 420 .

\section{Statistical analysis}

The data of $\operatorname{cof} D$ knock-out and wild-type strains were analyzed using the independent sample t-test of the SPSS statistical software (Version 20.0 for Windows; SPSS, Chicago, USA). The results were expressed as the mean and standard error of the mean (SEM). A significance level was indicated at $P<0.05$, and a trend was declared at $0.05 \leq P<0.10$.

\section{Results \\ Plasmid construction for knock-out cofD and PEASY-T1-cofD plasmid construction}

An 906 bp cofD gene fragment was successfully amplified from chromosome DNA of $M$. ruminantium using primers cofD designed. Amplification results are shown in Additional file 1: Fig. S1. The target gene cofD was ligated with the vector pEASY-T1 and confirmed by colony PCR. Six white monoclonal colonies grown on LB plates were randomly selected for further verification. DNA fragment sizes were observed in DNA electrophoresis analysis shown in Additional file 1: Fig. S2. The PCR products of positive clones were sequenced and the resulting sequences were subjected to nucleic acid sequence alignment. The results showed that the fragments were 
overlap by 828 bp (Identities $=821 / 828$ ) and the sequence similarity was 99\% (Additional file 1: Fig. S3).

\section{Plasmid pUC18-cofD-tet construction}

The pCU18-cofD-tet ligation product was cultured in LB solid medium containing tetracycline and then inoculated into tetracycline-containing LB liquid medium. The bacterial liquid was used as a template and the tetspecific primers were used to amplify tet. The results are shown in Additional file 1: Fig. S4. The 9 clones picked out showed clear bands between 1000 and $2000 \mathrm{bp}$. Compared with the PCR products of the tet gene, the sizes were identical, indicating that the tet and pUC18-cofD vectors were successfully constructed. The pUC18-cofDtet recombinant plasmid DNA was extracted from the above bacteria solution by an alkaline lysis method, and the extracted plasmid DNA was double digested with EcoRI and HindIII. The results are shown in Additional file 1: Fig. S5.

\section{Verification of cofD gene knock-out}

After the constructed pUC18-cofD-tet was transformed into the $M$. ruminantium by electrotransformation, the $100 \mu \mathrm{L}$ of culture solution was coated on a tetracycline plate, and the mutant strain was selected by static culture at $30^{\circ} \mathrm{C}$ for $72 \mathrm{~h}$. The expression level of cofD gene of mutant strain was lower $(P<0.05)$ than that of the wildtype strain (Fig. 1). Moreover, the expressing quantity of CofD enzyme protein in knock-out bacteria was significantly down-regulated $(P<0.05)$ as compared to the wildtype M. ruminantium (Fig. 2).

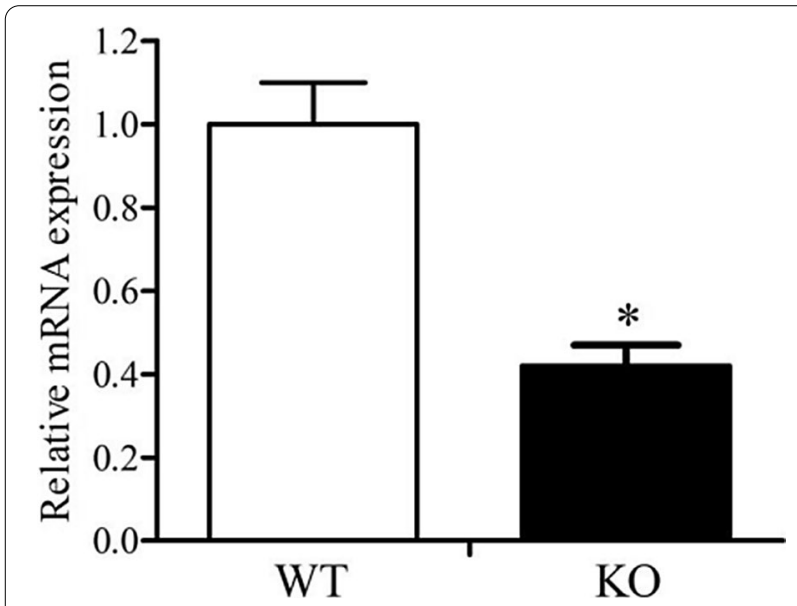

Fig. 1 The differences of mRNA expression (mean and SD) of cofD in WT and KO M. ruminantium. Strains were incubated at $30^{\circ} \mathrm{C}$ for $72 \mathrm{~h}$. SD standard deviation, WT wild-type, KO knock-out. The asterisk (*) indicates a significant difference $(P<0.05)$

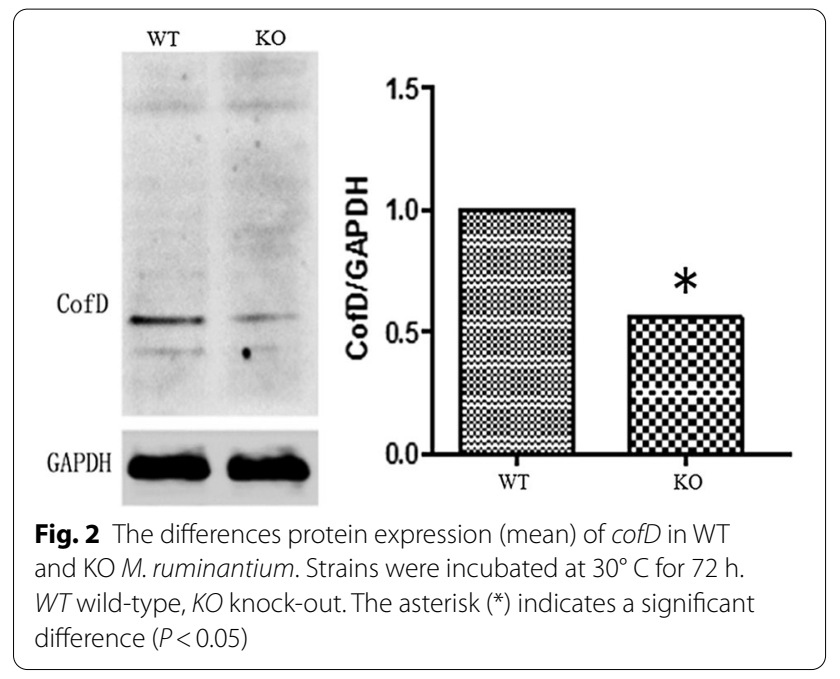

Effects of cofD knock-out on the growth of $M$. ruminantium The growth curves of wild-type and knock-out of $M$. ruminantium were respectively examined at $30{ }^{\circ} \mathrm{C}$ with equal inoculation amount (Fig. 3). After the cofD gene knock-out, the delay period of the mutant M. ruminantium was shorter than that of wild-type strains; besides, the $M$. ruminantium entered the logarithmic phase earlier. The logarithmic growth phase $(12 \mathrm{~h})$ of mutant $M$. ruminantium was lower in comparison with wild-type strains $(24 \mathrm{~h})$. As can be seen from Table 2, the maximal bacterial mass of cofD knock-out $M$. ruminantium was only approximately half of the wild-type strains, and the maximum specific growth rate was also lower $(P<0.05)$ than that of the wild-type strains.

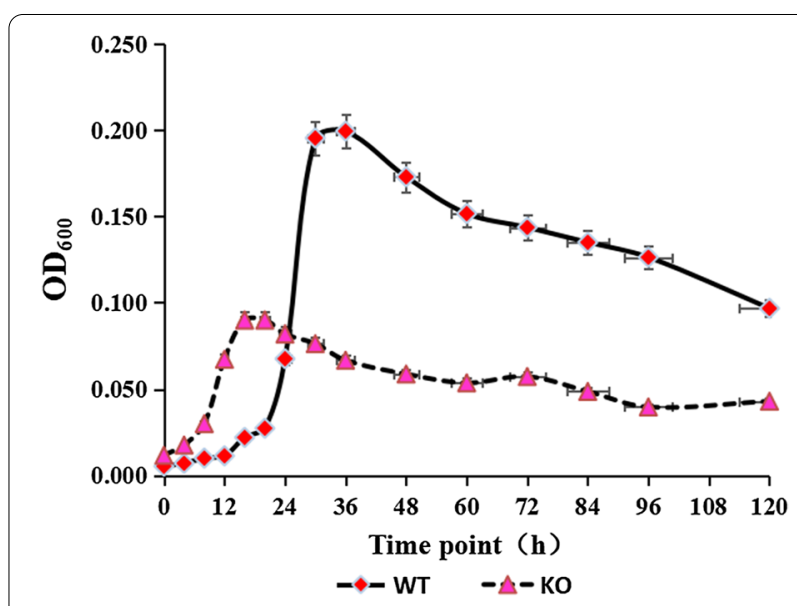

Fig. 3 Growth kinetics of WT and cofD KO strains of M. ruminantium grown in BJ medium at $39^{\circ} \mathrm{C}(n=3)$. Growth was determined by measuring the absorbance of the cultures at $600 \mathrm{~nm}$. WT wild-type, KO knock-out 
Table 2 Comparison in the methane production and growth indexes of wild-type and mutant M. ruminantium

\begin{tabular}{lllll}
\hline Indexes & \multicolumn{2}{l}{ Treatments } & SEM & $P$-Value \\
\cline { 2 - 3 } & WT & KO & & \\
\hline $\begin{array}{l}\text { The max amount } \\
\text { of bacteria (OD } \\
\text { value) }\end{array}$ & 0.200 & 0.090 & 0.003 & $<0.001$ \\
$\begin{array}{l}\text { The maximum spe- } \\
\text { cific growth rate }\end{array}$ & 0.017 & 0.008 & 0.001 & $<0.001$ \\
\hline
\end{tabular}

WT wild-type, KO knock-out, SEM standard error of the mean

Effects of cofD knock-out on the coenzyme $F_{420}$ synthesis of $M$. ruminantium

As shown in Fig. 4, the fluorescence value of $F_{420}$ was used to express the content of coenzyme $\mathrm{F}_{420}$ in this experiment. From the point view of growth of $M$. ruminantium, the coenzyme $\mathrm{F}_{420}$ content was increased gradually with the growth of the strain. From the total point of view (Fig. 4A), the content of coenzyme $\mathrm{F}_{420}$ in the cofD knock-out strains did not change significantly at $12 \mathrm{~h}(P>0.05)$. However, at 24, 36, 48, and $96 \mathrm{~h}$, the content of coenzyme $\mathrm{F}_{420}$ was significantly lower $(P<0.05)$ than that of wild-type $M$. ruminantium. Furthermore, the content of unit cell volume of coenzyme $\mathrm{F}_{420}$ between the cofD gene knock-out type and wild-type $M$. ruminantium at the same time point were analyzed (Fig. 4B). The content of coenzyme $\mathrm{F}_{420}$ per unit of biomass was decreased by $29 \%, 59 \%$, and $30 \%$ at 36,48 , and 96 h respectively. All of them were significantly lower $(P<0.05)$ in knock-out than those in wild-type strains.

\section{Effects of cofD knock-out on the methane production of $M$. ruminantium}

From the $\mathrm{CH}_{4}$ production and $\mathrm{H}_{2}$ consumption curve of the wild-type $M$. ruminantium, it can be seen that as the incubation time increases, the concentration of $\mathrm{H}_{2}$ in the

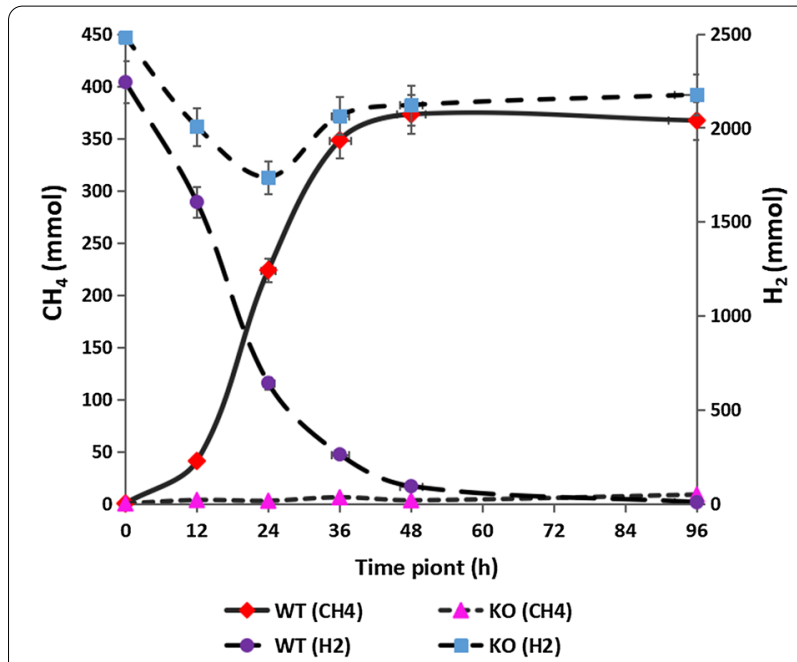

Fig. 5 The concentration changes of methane production and hydrogen consumption in WT and KO cofD type M. ruminantium at 5 time points $(12,24,36,48,96 \mathrm{~h})(\mathrm{n}=3)$. WT wild-type, KO knock-out

culture flask was continuously decreased, and the $\mathrm{CH}_{4}$ concentration was continuously increased (Fig. 5). The concentration of $\mathrm{CH}_{4}$ in the flasks reached a plateau at $48 \mathrm{~h}$. Comparing with $\mathrm{CH}_{4}$ production and $\mathrm{H}_{2}$ consumption of wild-type $M$. ruminantium, it was found that the cofD knockout strains only consumed a markedly lower amount of $\mathrm{H}_{2}$ in the logarithmic growth phase to generate trace amounts of $\mathrm{CH}_{4}$, and the maximum consumption of $\mathrm{H}_{2}$ and the maximum production of $\mathrm{CH}_{4}$ for $\operatorname{cofD}$ knock-out strains were only $14 \%$ and $2 \%$, respectively, of the wild-type strains.

\section{Discussion}

In recent years, $\mathrm{CH}_{4}$ emissions from ruminants have caused not only adverse effects on the environment, but also loss of energy intake by animals. Therefore, regulation of methanogens in the rumen has become a research
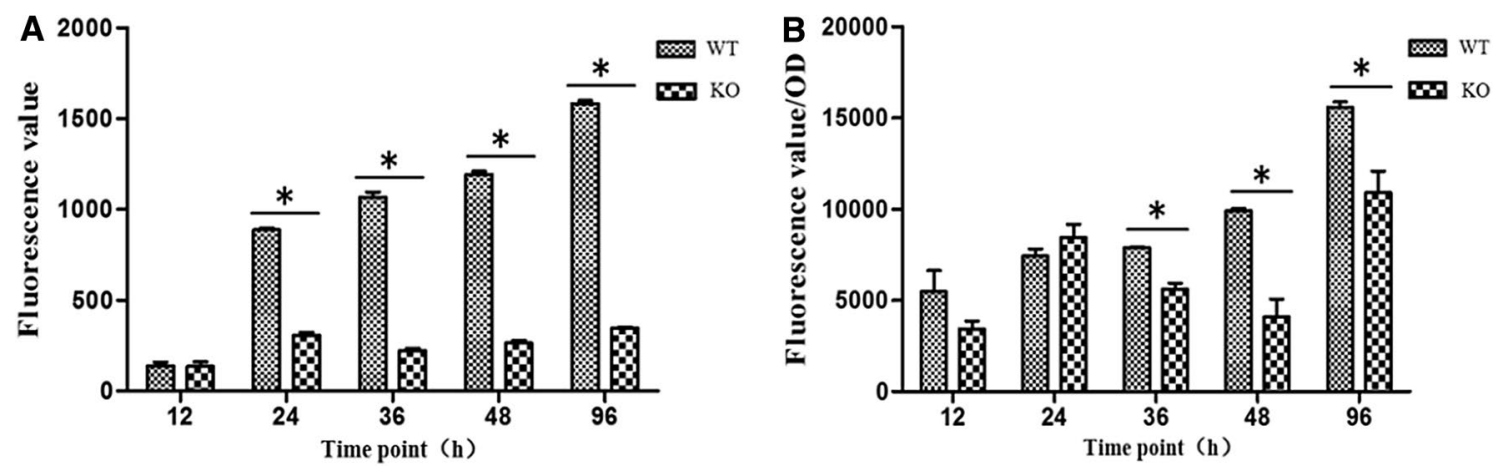

Fig. 4 The content (mean and SD) of coenzyme $\mathrm{F}_{420}$ of WT and KO M. ruminantium in different culture time. A the content of coenzyme $\mathrm{F}_{420}$ of liquid; $\mathbf{B}$ the content of coenzyme $\mathrm{F}_{420}$ per $\mathrm{OD}_{600}$. SD standard deviation, WT wild-type, KO knock-out 
hotspot. A previous study has compared the $16 \mathrm{~S}$ rRNA gene sequences of ruminal archaea derived from different ruminants and dietary compositions in 14 studies, and found that $92.3 \%$ of archaea in the rumen were originated from 3 genera, among which the Methanobrevibacter accounted for $61.6 \%$ and was the dominant methanogen in the gastrointestinal tracts of most herbivorous animals (Janssen and Kirs 2008).

As a strictly anaerobic bacteria, anaerobic condition is the key point to the successful cultivation of M. ruminantium. In the current experiment, the medium was boiled and deoxygenated. The anaerobic operation station was used for subpackage, inoculation, and incubation; besides, oxygen concentration was monitored in real-time using an oxygen controller to ensure strictly anaerobic conditions. The methanogens bacteria which is classified to Methanobacillus is mostly distributed in the two clades, including Smithii-gottschalkii-milleraethaurei clusters and Ruminantium-olleyae clusters, and The $M$. ruminantium belongs to Ruminantium-olleyae clusters (St-Pierre et al. 2015). The M. ruminantium, Methanobrevibacter thaueri, Methanobrevibacter smithii, and Methanosphaera stadtmanae of the Methanobacillus have been confirmed to be the main methanogens in the bovine rumen (Jarvis et al. 2000; Zhou et al. 2009; Wright et al. 2007). Due to the short reproductive cycle of the fast-growing methanogens and residence time of ruminal chyme, it is more conducive to the establishment of fast-growing methanogens. In this study, the $M$. ruminantium entered a platform period at approximately $24 \sim 36 \mathrm{~h}$. During the logarithmic growth phase, it consumed a large amount of $\mathrm{H}_{2}$, contributing to a lower level of hydrogen partial pressure in the rumen.

Methanal furans, tetrahydromethanopterin, coenzyme $\mathrm{F}_{420}$, coenzyme $\mathrm{M}$, HS-Coenzyme $\mathrm{B}$, and phenazine are closely related to the $\mathrm{CH}_{4}$ production of the methanogenic bacteria (Garcia et al. 2000). Among them, coenzyme $\mathrm{F}_{420}$ is a special low-potential electron carrier in high $\mathrm{G}+\mathrm{C}$ gram-positive bacteria such as archaea and mycobacteria. In the process of $\mathrm{CH}_{4}$ production of methanogenic bacteria, coenzyme $\mathrm{F}_{420}$ is involved in the hydrogen transfer reaction as a two-electron transporter. Its oxidation-reduction potential is $\mathrm{F}_{420} \mathrm{H}_{2} / \mathrm{F}_{420}+2^{\mathrm{e}-}(-360 \mathrm{mV})$, lower than $\mathrm{NAD}(\mathrm{P}) \mathrm{H} / \mathrm{NAD}(\mathrm{P})+2^{\mathrm{e}-}(-320 \mathrm{mV})$ and FADH $2+$ FAD2 $^{\mathrm{e}-}(-219 \mathrm{mV})$ (Purwantini and Mukhopadhyay 2009). The amino acid sequence of CofD enzyme is highly conserved among the archaea and bacterial organisms that produce coenzyme $\mathrm{F}_{420}$, but only weak sequence homologues appear in the thallus that do not produce coenzyme $\mathrm{F}_{420}$ (such as Bacillus) (Gorke et al. 2005). However, there are no other obligate anaerobic bacteria that contain coenzyme $\mathrm{F}_{420}$ and other substances that emit fluorescence at $480 \mathrm{~nm}$ and excitation wavelength is $420 \mathrm{~nm}$. Therefore, fluorescence microscopy to detect the fluorescence produced by colonies has become an important technique for the identification of methanogenic bacteria.

Gene knock-out is an essential biological method for studying gene function and has been widely used. Sendai et al. (2006) constructed a gene knock-out model of $\alpha$-1,3-galactosyltransferase on cattle by Cre/loxP method, which laid a foundation for application of multiple gene knock-outs in agricultural animals. Manabe et al. (2009) found that homologous knock-out of rinderpest virus could prevent bovine spontaneous prion encephalopathy and reduce the risk of bovine spontaneous encephalopathy. At the same time, study has also demonstrated that gene knock-out can block the formation of byproducts in microorganisms, thereby improving the yield and purity of the target product (Kim and Timmusk 2013). Gene knock-out provides new idea for biological research. However, few reports were carried out on the application of gene knock-out technology in the methane-related studies. In this research, homologous recombination technology was successfully used to screen the mutant strain of $M$. ruminantium in which cofD gene was knocked out, and the knock-out efficiency of screening was verified by PCR and enzyme digestion. In the process of gene knock-out vector construction, the pEASY$\mathrm{T} 1$ vector was selected as the cloning vector of the $\operatorname{cof} D$ gene. The pEASY-T1 vector contains the $\beta$-galactosidase gene (lacZ) and the ampicillin resistance gene. If an exogenous fragment is inserted into a multi-cloning site, the lac $\mathrm{Z}$ gene and $\beta$-galactosidase would be inactivated. Since white colonies were produced, blue-white screening of positive clones could be performed using Amp/ IPTG/X-gal selection medium. The pUC18 was used as a plasmid backbone, and a tetracycline gene was used as a resistance gene to construct a knock-out vector for $\operatorname{cof} D$ gene. This vector that was transformed into the M. ruminantium can not be replicated but has the opportunity to recombine with homologous genes homologously and express the tetracycline resistance, which can be selected. In this study, the cofD knock-out strains were selected, and the expression of cofD gene and CofD enzyme were significantly lower than those of wild-type strains.

Consistent with Liu and Whitman (2008) study, the results of current research displayed that in the logarithmic growth phase of wild-type $M$. ruminantium, it consumed greater amount of $\mathrm{H}_{2}$, which benefited to maintain a relatively lower level of $\mathrm{H}_{2}$ partial pressure in the rumen. The growth of strains was slower after the cofD gene knock-out. Moreover, the reproductive ability of strains was significantly reduced and it entered the logarithmic growth phase earlier. After entering the logarithmic growth phase, its coenzyme $\mathrm{F}_{420}$ content 
was significantly reduced, and only a small amount of $\mathrm{H}_{2}$ was consumed to produce $\mathrm{CH}_{4}$. The $\mathrm{F}_{420}$ is utilized in methanogens growth to oxidize their substrates. Thus, when the substrate is $\mathrm{H}_{2}$, the $\mathrm{H}_{2}$ can be coupled to reduce $\mathrm{F}_{420}$ by reducing $\mathrm{F}_{420}$ dehydrogenase (Frh) (Vitt et al. 2014). With knock-out of cofD, the M. ruminantium cell's redox driveability is reduced and lost partial ability to use $\mathrm{H}_{2}$, which may lead to a reduction in redox reaction of coenzyme $\mathrm{F}_{420}$ pool. Coenzyme $\mathrm{F}_{420}$ exists commonly in methanogens and its concentration in hydrogenotrophic methanogenic strain ranges from 100 to $400 \mathrm{mg} / \mathrm{kg}$ (Dolfing and Mulder 1985). The content of coenzyme $\mathrm{F}_{420}$ is different in varying species of methanogens. In addition, coenzyme $\mathrm{F}_{420}$ has been proved to be significantly higher in hydrogenotrophic methanogens than that in acetate-producing methanogens (Zábranská et al. 1985). In the study of M. machellae $\Delta$ Frh mutants, it was found that Frh was necessary for the growth of methanogens under $\mathrm{H}_{2} / \mathrm{CO}_{2}$ culture conditions (Kulkarni et al. 2009). The character of blue-green or green fluorescence under the $420 \mathrm{~nm}$ UV laser generated by coenzyme $\mathrm{F}_{420}$ and methyl thiophene compounds is used to identify the presence of methanogens. However, Dong et al. (2010) concluded that the fluorescence value of coenzyme $\mathrm{F}_{420}$ can be used as an index to measure the activity of methanogens when upflow anaerobic sludge blanket reactor is used to treat waste water in soybean production. Some other studies on anaerobic fermentation found that the changes in the content of coenzyme $\mathrm{F}_{420}$ can be used to determine the activity of methanogens (Dolfing and Mulder 1985; Wang et al. 2011). In the current study, the CofD enzyme expression that was the corresponding protein product of $\mathrm{F}_{420}$ was significantly reduced after knock-out of cofD gene. Meanwhile, the synthesis of methanogenic coenzyme $\mathrm{F}_{420}$ was significantly reduced, indicating that the knock-out of the cofD gene resulted in a slower reaction of catalyzing the condensation of LPPG and Fo to produce $\mathrm{F}_{420}$ (Graupner et al. 2002). The results further demonstrated that the CofD enzyme was a key enzyme for the biosynthesis of coenzyme $\mathrm{F}_{420}$.

In summary, our results showed that the growth and proliferation ability of $M$. ruminantium was decreased after $\operatorname{cofD}$ knock-out, subsequently, the production capacity of $\mathrm{CH}_{4}$ by utilizing $\mathrm{H}_{2}$ in the $M$. ruminantium was reduced. The cofD gene knock-out reduced the expression of CofD enzyme and the synthesis of coenzyme $\mathrm{F}_{420}$ in the $M$. ruminantium. Our result may provide new insights to clarify coenzyme $\mathrm{F}_{420}$ and cofD gene involved in the methanogenic mechanisms that can affect $\mathrm{CH}_{4}$ production by methanogen, helping to develop strategies to reduce $\mathrm{CH}_{4}$ emissions from ruminants.

\section{Supplementary Information}

The online version contains supplementary material available at https://doi. org/10.1186/s13568-021-01236-2.

Additional file 1: Fig. S1. Amplication of the cofD gene of M. ruminantium by using cofD primers. Fig. S2. The recombinant plasmid pEASY-T1-CofD was amplified using CofD-F and cofD-R as primers, and the transformants were identified by PCR. Fig. S3. PCR product sequencing of positive clones and comparison of similarities of cofD by Blast. Fig. S4. Identification of 9 monoclonal recombinant plasmids pUCl8-cofD-tet selected by PCR using tet specific primers. Fig. S5. Double digestion of pUCl8-cofD-tet recombinant plasmid DNA using EcoRI and Hindlll, detection by $1 \%$ agarose gel electrophoresis. (DOCX $437 \mathrm{~KB}$ )

\section{Acknowledgements \\ We would like to thank the Microbiology Research Institute of CSIRO for providing the parental M. ruminantium strain.}

\section{Authors' contributions}

$J M, X W$, and ZW conceived and designed the research. JM, XW, TZ, CT, XZ, $\mathrm{QP}, \mathrm{BX}$, and $\mathrm{LW}$ performed the experiment. JM, XW, $\mathrm{RH}$, and $\mathrm{HZ}$ analyzed the data. JM and XW wrote the original manuscript. JM, XW, and ZW reviewed the manuscript. All authors read and approved the final manuscript.

\section{Funding}

This research was funded by the National Natural Science Foundation of China (31272472) and China Agriculture (Beef Cattle/Yak) Research System of MOF and MARA (CARS-37).

\section{Availability of data and materials}

The data presented in this study are available on request from the corresponding author.

\section{Declarations}

Ethics approval and consent to participate

This article does not contain any studies with animals or human participants performed by any of the authors.

\section{Consent for publication}

Not applicable.

\section{Competing interests}

The authors declare no competing interests.

Received: 11 April 2021 Accepted: 15 May 2021

Published online: 28 May 2021

\section{References}

André-Denis GW, Klieve AV (2011) Does the complexity of the rumen microbial ecology preclude methane mitigation? Anim Feed Sci Technol 166:248-253

Balch WE, Wolfe RS (1977) New approach to the cultivation of methanogenic bacteria: 2-mercaptoethanesulfonic acid (HS CoM) dependent growth of Methanobacterium ruminantium in a pressurized atmosphere[J]. Appl Environ Microb 32(6):781-791

Benepal PK (2012) The rumen methanogen community and diurnal activity in pasture based dairy cows of the South Island. Doctoral thesis, Lincoln University, New Zealand

Cersosimo LM, Lachance H, St-Pierre B, van Hoven W, Wright ADG (2015) Examination of the rumen bacteria and methanogenic archaea of wild impalas (Aepyceros melampus melampus) from Pongola, South Africa. Microb Ecol 69(3):577-585

Choi KP, Bair TB, Bae YM, Daniels L (2001) Use of Transposon Tn5367 Mutagenesis and a Nitroimidazopyran-Based selection system to demonstrate a 
requirement for fbiA and fbiB in Coenzyme $\mathrm{F}_{420}$ Biosynthesis by Mycobacterium bovis BCG. J Bacteriol 183(24):7058-7066

Danielsson R, Schnurer A, Arthurson V, Bertilsson J (2012) Methanogenic population and $\mathrm{CH}_{4}$ production in Swedish dairy cows fed different levels of forage. Appl Environ Microb 78(17):6172-6179

Dolfing J, Mulder JW (1985) Comparison of methane production rate and coenzyme $\mathrm{F}_{420}$ content of methanogenic consortia in anaerobic granular sludge. Appl Environ Microb 49(5):1142-1145

Dong F, Zhao QB, Zhao JB, Sheng GP, Tang Y, Tong ZH, Yu HQ, Li YY, Harada H (2010) Monitoring the restart-up of an upflow anaerobic sludge blanket (UASB) reactor for the treatment of a soybean processing wastewater. Bioresource Technol 101(6):1722-1726

Eirich LD, Vogels GD, Wolfe RS (1978) Proposed structure for coenzyme $F_{420}$ from Methanobacterium. Biochemistry 17(22):4583-4593

Garcia J, Patel BKC, Ollivier B (2000) Taxonomic, phylogenetic, and ecological diversity of Methanogenic Archaea. Anaerobe 6(4):205-226

Gorke B, Foulquier E, Galinier A (2005) YvcK of Bacillus subtilis is required for a normal cell shape and for growth on Krebs cycle intermediates and substrates of the pentose phosphate pathway. Microbiology 151(11):3777-3791

Graupner M, White RH (2001) Biosynthesis of the phosphodiester bond in Coenzyme $\mathrm{F}_{420}$ in the Methanoarchaea. Biochemistry 40(36):10859-10872

Graupner M, Xu H, White RH (2002) Characterization of the 2-phospho-Llactate transferase enzyme involved in coenzyme $F_{420}$ biosynthesis in Methanococcus jannaschii. Biochemistry 41(11):3754-3761

Hook SE, Wright ADG, McBride BW (2010) Methanogens: methane producers of the rumen and mitigation strategies. Archaea 2010:945785

Huang GF, Wagner T, Ermler U, Shima S (2020) Methanogenesis involves direct hydride transfer from $\mathrm{H}_{2}$ to an organic substrate. Nat Rev Chem 4:213-221

Janssen PH, Kirs M (2008) Structure of the archaeal community of the rumen. Appl Environ Microb 74(12):3619-3625

Jarvis GN, Strömpl C, Burgess DM, Skillman LC, Moore ERB, Joblin KN (2000) Isolation and identification of ruminal methanogens from grazing cattle. Curr Microbiol 40(5):327-332

Johnson KA, Johnson DE (1995) Methane emissions from cattle. J Anim Sci 73(8):2483-2492

Kim SB, Timmusk S (2013) A simplified method for gene knockout and direct screening of recombinant clones for application in Paenibacillus polymyxa. PLOS ONE 8(6):e68092

Kulkarni G, Kridelbaugh DM, Guss AM, Metcalf WW (2009) Hydrogen is a preferred intermediate in the energy-conserving electron transport chain of Methanosarcina barkeri. Proc Natl Acad Sci 106(37):15915-15920
Li Z, Zhang Z, Xu C, Zhao J, Liu H, Fan Z, Yang F, Wright ADG, Li G (2014) Bacteria and methanogens differ along the gastrointestinal tract of Chinese Roe Deer (Capreolus pygargus). PLoS ONE 9(12):e114513

Liu YC, Whitman WB (2008) Metabolic, phylogenetic, and ecological diversity of the Methanogenic Archaea. Ann NY Acad Sci 1125:171-189

Manabe N, Li JY, Onoyama I, Sendai Y, Aoyagi Y, Onadera T, Yoshikawa Y (2009) Role of prion homo-knockout cattle on prevention of spontaneous bovine spongiform encephalopathy. P Korean Federation Sci Technol Soc 5:52-58

Martin C, Morgavi DP, Doreau M (2010) Methane mitigation in ruminants: from microbe to the farm scale. Animal 4(3):351-365

Purwantini E, Mukhopadhyay B (2009) Conversion of $\mathrm{NO}_{2}$ to $\mathrm{NO}$ by reduced coenzyme $\mathrm{F}_{420}$ protects mycobacteria from nitrosative damage. Proc Natl Acad Sci 106(15):6333-6338

Sendai Y, Sawada T, Urakawa M, Shinkai Y, Kubota K, Hoshi H, Aoyagi Y (2006) Alpha 1,3-galactosyltransferase-gene knockout in cattle using a single targeting vector with loxP sequences and cre-expressing adenovirus. Transplantation 81(5):760-766

St-Pierre B, Cersosimo LM, Ishaq SL, Wright ADG (2015) Toward the identification of methanogenic archaeal groups as targets of methane mitigation in livestock animals. Front Microbiol 6:776

Vitt S, Ma K, Warkentin E, Moll J, Pierik AJ, Shima S, Ermler U (2014) The $\mathrm{F}_{420}$-reducing [NiFe]-Hydrogenase complex from Methanothermobacter marburgensis, the first X-ray structure of a Group 3 Family Member. J Mol Biol 426(15):2813-2826

Wang MZ, Wang S, Pan XH, Wang HR, Wang JQ (2011) Supplementation of four different oils affects gas production and coenzyme $\mathrm{F}_{420}$ of ruminal microbe in vitro. Chin J Anim Nutr 23(10):1819-1825

Wright ADG, Auckland CH, Lynn DH (2007) Molecular diversity of methanogens in feedlot cattle from Ontario and Prince Edward Island, Canada. Appl Environ Microb 73(13):4206-4210

Zábranská J, Schneiderová K, Dohányos M (1985) Relation of coenzyme $\mathrm{F}_{420}$ to the activity of methanogenic microorganisms. Biotechnol Lett 7(8):547-552

Zhou M, Hernandez-Sanabria E, Guan LL (2009) Assessment of the microbial ecology of ruminal methanogens in cattle with different feed efficiencies. Appl Environ Microb 75(20):6524-6533

\section{Publisher's Note}

Springer Nature remains neutral with regard to jurisdictional claims in published maps and institutional affiliations.

\section{Submit your manuscript to a SpringerOpen ${ }^{\circ}$ journal and benefit from:}

- Convenient online submission

- Rigorous peer review

- Open access: articles freely available online

- High visibility within the field

- Retaining the copyright to your article

Submit your next manuscript at $\boldsymbol{\nabla}$ springeropen.com 